\title{
The Handsome Cross Grasshopper Oedaleus decorus (Germ.) (Orthoptera: Acrididae) as A Newly Emerging Pest in the Southe-Astern Part of West Siberian Plain ${ }^{+}$
}

\author{
Kristina V. Popova ${ }^{1}$, Natalia S. Baturina ${ }^{1,2}$, Vladimir V. Molodtsov ${ }^{1}$, Oxana V. Yefremova ${ }^{1}$, Vasily D. Zharkov ${ }^{1}$ and \\ Michael G. Sergeev ${ }^{1,2, *}$
}

Citation: Popova, K.V.; Baturina, N.S.; Molodtsov, V.V.; Yefremova, O.V.; Zharkov, V.D.; Sergeev, M.G. The Handsome Cross Grasshopper Oedaleus decorus (Germ.) (Orthoptera: Acrididae) as A Newly Emerging Pest in the Southe-Astern Part of West Siberian Plain, in Proceedings of the 1st International Electronic Conference on Entomology, 1-15 July 2021, MDPI: Basel, Switzerland, doi:10.3390/IECE-10493

Published: 1 July 2021

Publisher's Note: MDPI stays neutral with regard to jurisdictional claims in published maps and institutional affiliations.

Copyright: () 2021by the authors. Submitted for possible open access publication under the terms and conditions of the Creative Commons Attribution (CC BY) license (http://creativecommons.org/licenses /by/4.0/).
1 Department of General Biology and Ecology, Novosibirsk State University,

2 Pirogova Street, Novosibirsk 630090, Russia; kristin_belle@mail.ru

2 Laboratory of Invertebrate Ecology, Institute of Systematics and Ecology of Animals, Siberian Branch, Russian Academy of Sciences,11 Frunze Street, Novosibirsk 630091, Russia; mgsergeev@aol.com

* Correspondence: mgs@fen.nsu.ru; mgsergeev@aol.com

+ Presented at the 1st International Electronic Conference on Entomology (IECE 2021), 1-15 July 2021; Available online: https://iece.sciforum.net/.

\begin{abstract}
Oedaleus decorus is a widely distributed species over the Eurasian semi-arid territories, from the Atlantic coast to the Pacific one. In many semi-arid territories, O. decorus was and is the important pest. In the south-eastern part of West Siberian Plain, until the 1960s it was not considered a pest. We compared two sets of data on the acridid distribution in the region: until the 1950s and from the 1960s until 2019. Until the 1960s the species occurred mainly in the southern steppes. Since the 1960s its distribution changed significantly. Nowadays it occupies almost all local steppes and the southern part of the forest-steppes and was also found on the eastern side of the Ob River. These shifts may be explained by both climatic changes and changes in human activities. During upsurges the densities of $O$. decorus were often more than 1-2 adults per square meter. It was and is often abundant in the same habitats and in the same periods as the Italian locust (Calliptamus italicus) one of the most important pest. This means during joint outbreaks these two species can simultaneously damage almost all spectrum of plants.
\end{abstract}

Keywords: distribution; range; dispersal; South Siberia; dynamics; population; plant protection; outbreak; Italian locust

\section{Introduction}

Oedaleus decorus (Germar, 1825) or the handsome cross grasshopper is a widely distributed species over the Eurasian semi-arid territories (mainly across forest-steppes, steppes, semi-deserts, Mediterranean and mountain dry grasslands), from the Atlantic coast to the Pacific one [1-4]. It also occurs in North Africa, on the Canary Islands, and on Madeira [1]. This grasshopper is usually univoltine with overwintering eggs. This species prefers to feed on different grasses $[5,6,7]$. During outbreaks it can seriously damage cereals, pastures, and hayfields [5,8]. Besides, it may damage cotton, alfalfa, different legumes, sugar beet, vegetables, vine, and some fruit trees [5]. In many semi-arid territories, O. decorus was and is the important pest [9-11], especially in the eastern part of its range $[12,13]$. However, in the south-eastern part of West Siberian Plain, one of the main agricultural region of Russia, according R. Berezhkov [14] until the 1960s this species occurred mainly in the dry (southern) steppes, its abundance was low, and it was not considered as a pest. During the 20th century ecosystems of this region have been significantly changed by human activity. In the second half of the last century, such ecosystems' 
transformations resulted in species distribution changes [15]. The aim of this publication is to show how the distribution of O. decorus over West Siberian Plain has shifted.

\section{Materials and Methods}

Original data were collected from 1979 until 2019 in the south-eastern part of West Siberian Plain. This territory borders the Irtysh River to the west and south-west and the mountains of South Siberia to the east and south-east. Its northern boundary is approximately defined by the southern border of the taiga life zone. Originally this area was characterized by grasslands and forests. Later the south-eastern part of West Siberian Plain was mainly converted to agricultural lands (fields and pastures).

The peculiarities of grasshoppers' distribution were characterized by quantitative and qualitative samples collected in natural and transformed ecosystems, usually in July and August when adults were dominated [2,3,15]. Samples captured during a fixed period of time were done in every habitat studied $[2,16,17]$. Using this method, insects were collected with a standard net ( $40 \mathrm{~cm}$ diameter) over a period of 10-30 minutes. Results for each habitat were transformed to an hour. In many cases, especially during locust outbreaks, we also counted acridid densities on arbitrarily placed plots $0.25 \times 0.25 \mathrm{~m}^{2}$ (in some cases $\left.-0.5 \times 0.5 \mathrm{~m}^{2}\right)[4,18-20]$.

We also analyzed some old data, especially collected by the expeditions of Novosibirsk State University (1961-1980) and checked some previous species identifications. We used the Glonass/GPS navigators to determine geographical coordinates of localities. For localities explored before 2000 we used Google Earth Pro (CGoogle, 2020) to get the same parameters. The main part of studied specimens is in the collections of Novosibirsk State University and the Institute of Systematics and Ecology of Animals (Novosibirsk). We also used data from different publications for the first half of the 20th century [14,21-25] and data for some specimens from the collections of Zoological Institute, Russian Academy of Sciences (Saint Petersburg, Russia), and Berezhkov's collections at Tomsk State University (Tomsk, Russia). The geographic coordinates for almost all old localities of grasshoppers (> 134) were determined. These data were compared with data for 1961-2019 (162 localities for all acridid insects). Maps of species distribution were produced on the basis of geographic coordinates with MapInfo 12.03.

\section{Results}

Until the middle of the 20th century, O. decorus was mainly distributed in the southern parts of the region (Figure 1) and was commonly associated with the dry steppes. Its northernmost localities were found near the 53th parallel north in the so-called Kulunda steppe between the Irtysh and Ob Rivers [14]. The only known exception was the locality in the vicinities of Omsk (about $55^{\circ} \mathrm{N}$ - the forest-steppes of the Irtysh River basin) $[25,26]$. Bey-Bienko [25] found this species near Omsk on the dry southern slope on the right (eastern) side of the Irtysh River. He noted that $O$. decorus was very rare.

Our data show that in the 1970s, the species occurred already across the whole Kulunda steppe (up to $54^{\circ} \mathrm{N}$ ). In the 1990s, O. decorus crossed the 54th parallel and its populations were observed in the southern parts of the forests-steppe. In 1999, its specimen was found in the southern part of Novosibirsk, in Novosibirsk Scientific Center of Russian Academy of Sciences (so-called Akademgordok) [27], on the right (eastern) side of the $\mathrm{Ob}$ River. This locality became the north-easternmost one on West Siberian Plain. Later several colonies of this species were observed in the forest-steppes on the right side of the $\mathrm{Ob}$ River. They were commonly associated with dry transformed habitats, e.g., with overgrazed meadow steppes, lawns, and roadsides. 
Hence, nowadays $O$. decorus became the widely distributed grasshopper over the south-eastern parts of West Siberian Plain and occupies all steppe areas and the southern parts of the forest-steppes between the Irtysh and Ob Rivers. Besides, it also spread across the forest-steppes on the eastern side of the Ob River and colonized some transformed habitats.

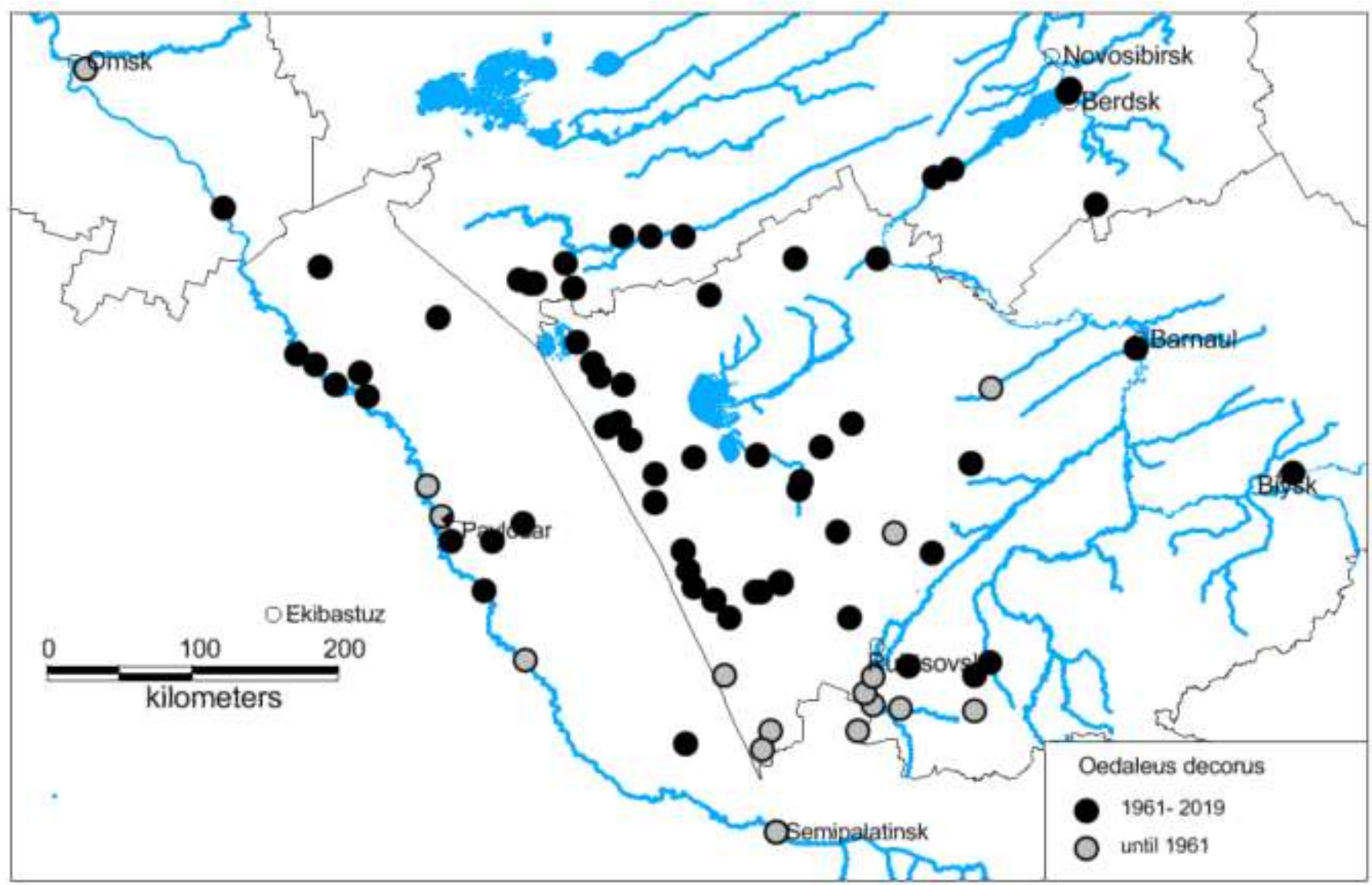

Figure 1. Distribution of Oedaleus decorus over the south-eastern part of West Siberian Plain until the 1960s and after 1961.

In the 1920s, the abundance of O. decorus was relatively low. Bey-Bienko [25] noted that this species was relatively numerous only on the sandy dunes in the southern part of the Kulunda steppe in Kazakhstan, and rare in some adjacent habitats with dominance of short grasses and sagebrushes. However, O. decorus was very common in the semi-deserts of East Kazakhstan.

In the end of the 20th century and in the beginning of the 21th century, the handsome cross grasshopper became very abundant in the steppe habitats, especially during warm and dry summers. During the Italian locust outbreaks, its abundance may be very high and comparable with the abundance of Calliptamus italicus (Table 1). The Spearman rankorder correlation coefficient for the long-term dynamics of populations of $O$. decorus and C. italicus is relatively high for each plot studies (Table 1) and very high if we summarize data for all plots $\left(\mathrm{r}_{\mathrm{s}}=0.917, \mathrm{p}<0.001\right)$.

Table 1. Dynamics of the average abundance (ind. per hour) of $O$. decorus relative to the average abundance of the Italian locust in the Kulunda steppe.

\begin{tabular}{|c|c|c|c|}
\hline Year & $\begin{array}{l}\text { Aleksandrovskij } \\
53.67^{\circ} \mathrm{N} 78.25^{\circ} \mathrm{E}, \\
\text { northern steppe }\end{array}$ & $\begin{array}{c}\text { Yarovoe } \\
52.85^{\circ} \mathrm{N} 78.57^{\circ} \mathrm{E}, \\
\text { dry steppe }\end{array}$ & $\begin{array}{l}\text { Ust-Volchikha } \\
51.93^{\circ} \mathrm{N} 80.28^{\circ} \mathrm{E} \\
\text { dry steppe }\end{array}$ \\
\hline 2000 & $1146 / 2682$ & $252 / 582$ & 474 / 144 \\
\hline
\end{tabular}




\begin{tabular}{cccc}
\hline 2001 & $210 / 246$ & $54 / 450$ & $24 / 234$ \\
\hline 2002 & $6 / 0$ & $0 / 24$ & $72 / 42$ \\
\hline 2003 & $6 /+$ & $0 / 4$ & $6 / 6$ \\
\hline 2004 & $0 /+$ & $0 / 4$ & $0 /+$ \\
\hline 2005 & $0 / 24$ & $54 / 6$ & $0 / 0$ \\
\hline 2006 & $0 / 18$ & $60 / 30$ & $6 / 0$ \\
\hline 2007 & $18 / 84$ & $150 / 60$ & $20 /+$ \\
\hline 2008 & $60 / 78$ & $144 / 6$ & $40 / 0$ \\
\hline 2015 & $+/+$ & $4 / 0$ & $204 / 480$ \\
\hline 2018 & $+/ 6$ & $?$ & $17.2 / 17.1$ \\
\hline $\begin{array}{c}\text { Spearman's cor- } \\
\text { relation }\end{array}$ & 0.586 & 0.609 & 0.518 \\
\hline & $(p=0.058)$ & $(p=0.063)$ & $(p=0.102)$ \\
\hline
\end{tabular}

Abundance of O. decorus / abundance of the Italian locust; + - one or several specimens were found beyond counts; ? - no data.

\section{Discussion}

In the first half of the 20th century, some specimens of the genus Oedaleus Fieber from West Siberian Plain were misidentified as O. infernalis Saussure [14]. We checked such specimens from Berezhkov's collections (Tomsk State University, Tomsk, Russia). All of them proved to be $O$. decorus. To distinguish similar specimens and the true individuals of O. infernalis from East Asia Bey-Bienko[28] described the new species, O. asiaticus BeyBienko. Later Ritchie [1] revised the genus and showed that $O$. asiaticus is conspecific with O.decorus. He noted very significant variability of individuals of $O$. decorus from different parts of its range. Some orthopterists $[12,29,30]$ follow this proposal, and our data support this point of view [31]. However, some others [32] don't. Molecular data don't allow us to solve this problem up to date. Fries et al. [33] showed that $O$. decorus and O. asiaticus are close forms, however should be considered as separate species. Kindler et al. [34] hypothesized that in the species complex, there are three distinct, but closely related species or subspecies. Later Schmid et al. [35] also described similarity between O. decorus decorus from Europe and O. decorus asiaticus. That is why we prefer to follow the most comprehensive revision of the genus [1,31].

The handsome cross grasshopper is very widely distributed in the southern part of the Palaearctic Region, from South and Central Europe, through North Kazakhstan, South Siberia and Mongolia to North and North-East China, and from North Africa, through Asia Minor, Levant, Caucasus, Iran, South Kazakhstan, Tien Shan, Pamiro-Alay, Kopetdagh, North Afghanistan, Xinjiang, to E China [1-4,31]. The species is also found on the Canary Islands and on Madeira [1].

In Europe, the northern boundary of its range crossed France, Switzerland, Slovakia [1], North Ukraine, and European Russia (Orel, Tambov, and Samara Province) [36]. B. Uvarov [36] also noted that the species occurred in the Moscow Province, however this mention is uncertain [37]. In the steppes of South Siberia, the species was distributed up to Kurgan, Omsk, Minussinsk and Transbaikal area [37].

In the end of the last century and in the beginning of the 21th century, the species distribution over Central Europe didn't change significantly [38]. O. decorus is also found in the Lipetsk and Tambov Regions of Russia [39]. The northern boundary of its range remains almost the same in South Siberia as well $[1,2,31]$. However, in the Volga River Basin (eastern part of European Russia), in the second half of the 20th century, several sporadic colonies of this species were found in the taiga life zone of the Kirov Region [40]. $O$. decorus also became widely distributed in the Republic of Tatarstan [41]. Similar changes are described for the south-eastern part of West Siberian Plain as well (see Results).

O. decorus is one of the most common and widely distributed species in the dry steppes of the south-eastern parts of West Siberian Plain, but nowadays it is often one of 
the dominants in the typical and meadow steppes as well. During upsurges the density of its adults is commonly about 1-2 per square meter. However, our data show that sometimes its density may be more than 10 adults per square meter. In many cases, some overlapping of outbreaks of the Italian locust and O. decorus was observed, especially in the dry steppes and semi-deserts of Russia and Kazakhstan. As a result, these two species may damage almost all spectrum of cultivated plants, pastures and hayfields. Besides, $O$. decorus asiaticus or the Mongolian locust is one of most important pests in the eastern parts of the steppe life zone [13,42-44]. Some morphological and behavioral traits of the locusts are also revealed in local populations of this subspecies $[13,42,44]$. Further, in the steppes, during outbreaks hoppers and especially adults of $O$. decorus can actively migrate from one habitat to others as well $[11,13]$.

\section{Conclusions}

Since the 1960s, in the south-eastern parts of West Siberian Plain, the distribution pattern of the handsome cross grasshopper changed significantly. Nowadays O. decorus occupied almost all local steppes and the southern part of the forest-steppes, up to $55^{\circ} \mathrm{N}$, and spread over the forest-steppes on the right (eastern) side of the Ob River too. These changes may be explained by both climatic changes (especially northward) and some transformations in human activities (mainly for eastward spreading). One can suppose that in the nearest future this species will continue to spread eastward and penetrate into the so-called Kuznetsk steppe in the Kemerovo Region.

The species became very common and occurs in almost all steppe habitats in the steppe life zone and on plots with xerophytic and mesoxerophytic vegetation (especially overgrazed meadows, roadsides, and dry lawns) on the eastern side of the Ob River. In 1999-2002 the abundance of O. decorus was very high in the Kulunda steppe between the Irtysh and Ob Rivers. This period of its long-term dynamics may qualified as the local outbreak. It is vitally important that local populations of $O$. decorus often became very abundant in the same habitats and in the same periods as the Italian locust (C. italicus) one of the most important pest in the region. In this case, the situation for plant protection services may be very complicated, because the handsome cross grasshopper (O. decorus) is more or less typical grass feeder, while the Italian locust prefers dicots. This means during joint outbreaks these two species can simultaneously damage almost all spectrum of agricultural plants, pastures, and hayfields. Besides, in the local steppe populations, there is some opportunity of prospective emergence of certain peculiarities of gregarization as described for populations of O. decorus asiaticus in Inner Mongolia [13,42-44].

Author Contributions: Field collecting of grasshoppers, geographic coordinate determination, specimen identification, all authors; conceptualization, methodology, supervision, project administration, funding acquisition, writing, M.S.; old data analysis, K.P.; coordinate checking, map producing, writing - editing, V.M.; general discussion, K.P.; O.Y.; N.B.; V.Z. All authors have read and agreed to the published version of the manuscript.

Funding: These studies were financially supported by the joint program of the Russian Foundation for Basic Researches and the Government of Novosibirsk Region (18-416-540001 and 20-416-540004), and also by the Federal Fundamental Scientific Research Program (FWGS-2021-0002).

Institutional Review Board Statement: Not applicable.

Informed Consent Statement: Not applicable.

Data Availability Statement: Not applicable.

Acknowledgments: We thank all our colleagues and students (especially O. Denisova, O. Ermolaeva, and I. Vanjkova) for their valuable help during collecting field data. We are also indebted to all companions during our numerous field trips. We wish to express our special thanks to the late L.L. Mistshenko (Saint Petersburg), the late I.V. Stebaev (Novosibirsk), and the late G.P. Ostroverkhova (Tomsk) for their cooperation.

Conflicts of Interest: The authors declare no conflict of interest. 


\section{References}

1. Ritchie, J.M. A taxonomic revision of the genus Oedaleus Fieber (Orthoptera: Acrididae). Bull. Br. Mus. (Nat. Hist.). Entomol. 1981, 42(3), 83-183.

2. $\quad$ Sergeev, M.G. Patterns of Orthoptera Distribution in North Asia; Nauka Publ.: Novosibirsk, Russia, 1986; p. 237. (In Russian).

3. Sergeev, M.G. Ecogeographical distribution of Orthoptera, In The Bionomics of Grasshoppers, Katydids and Their Kin; Gangwere, S.K., Muralirangan, M.C., Muralirangan, M., Eds. CAB International: Oxon, UK/NewYork, NY, USA, $1997 ;$ pp.129-146.

4. Storozhenko, S.Yu. Locusts and Grasshoppers Pests of U.S.S.R. Orthopterists' Society: Ste-Anne-de-Bellevue, Québec, Canada, 1991; p. 89.

5. Mistshenko, L.L. Orthoptera (Saltatoria), In Insects and Mites - Pests of Agriculture Crops; Kryzhanovsky, O.L., Danzig, E.M., Eds. Nauka Publ.: Leningrad, Russia, 1972; Volume 1; pp. 16-115. (In Russian).

6. Stebaev, I.V., Pshentsyna, L.B. Food selectivity of dominant grasshopper species in the steppes and the flood-plain meadows near the Irtysh River based on the botanical analysis of their feces, In Issues of Ecology: Species, Population, Community; Stebaev, I.V. Ed. Novosibirsk State University: Novosibirsk, Russia, 1978; pp. 18-59. (In Russian).

7. Pshentsyna, L.B. Trophic specialization of grasshoppers in a habitat and their influence on vegetation, In Issues of Ecology: Behavior and Ecology of Insects Associated with Agrobiogeocoenoses; Stebaev, I.V. Ed. Novosibirsk State University: Novosibirsk, Russia, 1981; pp. 66-84. (In Russian).

8. Sergeev, M.G. Handsome cross grasshopper Oedaleus decorus (Germar, 1825) (Acrididae), In Encyclopedia of Pest Orthoptera of the World; Lecoq, M., Zhang, L., Eds. China Agricultural University Press: Beijing, PRC, 2019; pp. 165-169.

9. Predtechensky, S.A.; Zhdanov, S.P.; Popova, A.A. Pest locusts in the USSR. Tr. Po Zastshite Rastenij. Ser. Entomol. 1935, 18, 1168. (In Russian).

10. The Locust and Grasshopper Agricultural Manual. Centre for Overseas Pest Research: London, UK, $1982 ;$ p. 690.

11. Latchininsky, A.V.; Sergeev, M.G.; Childebaev, M.K.; Chernijakhovskij, M.E.; Lockwood, J.A.; Kambulin, V.E.; Gapparov, F.A. The Grasshoppers of Kazakhstan, Middle Asia and Adjacent Territories; Association for Applied Acridology International \& University of Wyoming: Laramie, WY, USA, 2002; p. vii + 387. (In Russian).

12. Chen, Y. The Main Acridoids and Ecological Management of Locust Plagues in China. Science Press: Beijing, PRC, 2005, p.vii +361. (In Chinese).

13. Le Gall, M.; Overson, R.; Cease, A. A global review on locusts (Orthoptera: Acrididae) and their interactions with livestock grazing practices. Front. Ecol. Evol. 2019, 7, 263, doi:10.3389/fevo.2019.00263.

14. Berezhkov, R.P. The grasshoppers of West Siberia; Tomsk University Publ.: Tomsk, Russia, 1956; p. 174. (In Russian).

15. Sergeev, M.G. Distribution patterns of grasshoppers and their kin over the Eurasian Steppes. Insects 2021, 12, 77, doi: 10.3390/insects12010077.

16. Gause, G.F. Studies on the ecology of the Orthoptera. Ecology 1930, 11, 307-325, doi:10.2307/1930266.

17. Sergeev, M.G.; Denisova, O.V.; Vanjkova, I.A. How do spatial population structures affect acridid management? In: Grasshoppers and Grassland Health: Managing Grasshopper Outbreaks without Risking Environmental Disaster; Lockwood, J.A., Latchininsky, A.V., Sergeev, M.G., Eds. Kluwer Academic Publishers: Dordrecht, The Netherlands, et al., 2000; pp. 71-87, doi:10.1007/978-94-0114337-0_5.

18. Sergeev, M.G.; Van'kova, I.A. The dynamics of a local population of the Italian locust (Calliptamus italicus L.) in an anthropogenic landscape. Contemp. Probl. Ecol. 2008, 1(1), 88-95, doi:10.1134/S1995425508010098.

19. Sergeev, M.G.; Van'kova, I.A. Dynamics of the Italian locust Calliptamus italicus L. population in the southeast of the West Siberian Plain. Contemp. Probl. Ecol. 2008, 1(2), 204-209, doi:10.1134/S1995425508020057.

20. Sergeev, M.G. Ups and downs of the Italian locust (Calliptamus italicus L.) populations in the Siberian steppes: On the horns of dilemmas. Agronomy 2021, 11, 746. doi:10.3390/agronomy11040746.

21. Tarbinskij, S.P. Materials concerning the orthopterous fauna of the Province of Altai. Rev. Russ. Entom. 1925, 19, 176-195. (In Russian).

22. Wnukowskij, W. Zur Fauna der Orthopteren and Dermapteren des Besirks Kamenj (südwestrliches Sibirien, früheres Gouvernement Tomsk). Mitt. Münch. Ent. Ges. 1926, 5, 87-92.

23. Bey-Bienko, G.Ya. A review of Dermaptera and Orthoptera fauna of Omsk Region. Tr. Po Zastshite Rasteniy Seriya Entomol. 1930, 1(1), 161-177. (In Russian).

24. Bey-Bienko, G.Ya. Materials concerning the Orthoptera of the District of Semipalatinsk. News of West-Siberian Geographic Society 1930, 7, 189-214. (In Russian).

25. Bey-Bienko, G.Ya.The zonal and ecological distribution of Acrididae in West Siberian and Zaisan Plains. Tr. Po Zastshite Rasteniy Seriya Entomol. 1930, 1, 51-90. (In Russian).

26. Lavrov, S.D. Orthoptera (Saltatoria) of the vicinities of Siberian Agricultural Academy. Proc. Siberian Agricultural Academy 1924, 3, 85-88. (In Russian).

27. Sergeev, M.G. New data about Orthoptera of the Novosibirsk vicinities. Euroasian Entomological Journal 2004, 3(3), 173-174. (In Russian).

28. Bey-Bienko, G.Ya. New and little-known Orthoptera found in the USSR. Zapiski Leningradskogo Selskokhozjastvennogo Instituta 1941, 4, 147-159. (In Russian).

29. Ma, Y., Li, H., Kang, L. The Grassland Insects of Inner Mongolia; Tianze Eldonejo: Beijing, 1991, p. xiv + 467. (In Chinese). 
30. Zheng, Zh., Xia, K. Eds. Fauna Sinica. Insecta. Vol. 10. Orthoptera. Acridoidea. Oedipodidae and Arcypteridae; Science Press: Beijing, 1998, p. xv + 616. (In Chinese).

31. Sergeev, M.G.; Storozhenko, S.Yu.; Benediktov, A.A. An annotated check-list of Orthoptera of Tuva and adjacent regions. Part 3. Suboder Caelifera (Acrididae: Gomphocerinae: Gomphocerini; Locustinae). Far East. Entomol. 2020, 402, 1-36, doi:10.25221/fee.402.1.

32. Cigliano, M.M.; Braun, H.; Eades, D.C.; Otte, D. Orthoptera Species File. Version 5.0/5.0. 2021. Available online: http://Orthoptera.SpeciesFile.org (accessed on 5 June 2021).

33. Fries, M., Chapco, W., Contreras, D. A molecular phylogenetic analysis of the Oedipodinae and their intercontinental relationships. J. Orthoptera Res. 2007, 16(2), 115-125, doi:10.1665/1082-6467(2007)16[115:AMPAOT]2.0.CO;2.

34. Kindler, E., Arlettaz, R., Heckel, G. Deep phylogeographic divergence and cytonuclear discordance in the grasshopper Oedaleus decorus. Mol. Phylogenet. Evol. 2012, 65, 695-704, doi: 10.1016/j.ympev.2012.07.025.

35. Schmid, S., Neuenschwander, S., Pitteloud, C., Heckel, G., Pajkovic, M., Arlettaz, R., Alvarez, N. Spatial and temporal genetic dynamics of the grasshopper Oedaleus decorus revealed by museum genomics. Ecol. Evol. 2018, 8(3), 1480-1495, doi:10.1002/ece.3.3699.

36. Uvarov, B.P. Grasshoppers of the European Part of the USSR and West Siberia; Novaya Derevnja: Moscow, Russia, 1925; p. 120. (In Russian).

37. Bey-Bienko, G.Ya..; Mistshenko, L.L. Locusts and Grasshoppers of the USSR and Adjacent Countries; USSR Academy of Science Publ.: Moscow/Leningrad, Russia, 1951; Volume 1-2; p. 667. (In Russian).

38. Kuřavová, K. The grasshopper Oedaleus decorus in the Czech Republic (Orthoptera: Acrididae). Klapalekiana $2015,51,55-60$.

39. Mikhailenko, A.P., Bolshakov, L.V. New findings of Oedaleus decorus (Germar, 1817) (Orthoptera: Acrididae) in the forest-steppe of central European Russia. Eversmannia 2014, 39, 45. (In Russian).

40. Kopysov, V.A. Orthoptera, In Fauna of the Kirov Oblast; Shernin, A.I. Ed. Kirov State Teacher Institute: Kirov, Russia, 1974, 2, 3147. (In Russian).

41. Karmazina, I.O., Shulaev, N.V. Orthopterous insects (Orthoptera) from the central part of the Volga-Kama Region: Faunistic barriers and zoogeographical zoning. Proc. Kazan University, Nat. Sci. 2014, 156(2), 110-126. (In Russian).

42. Cease, A.J., Hao, S., Kang, L., Elser, J.J., Harrison, J.F. Are color or high rearing density related to migratory polyphenism in the band-winged grasshopper, Oedaleus asiaticus? J. Insect Physiol. 2010, 56, 926-936, doi:10.1016/j.jinsphys.2010.05.020.

43. Qin, X., Wu, H., Huang, X., Lock, T.L., Kallenbach, R.L., Ma, J., Ali, M.P., Tu, X., Cao, G., Wang, G., Nong, X., McNeill, M.R., Zhang., Z. Plant composition changes in a small-scale community have a large effect on the performance of an economically important grassland pest. BMC Ecol. 2019, 19, 32, doi:10.1186/s12898-019-0248-6.

44. Cease, A.J., Harrison, J.F., Hao, S., Niren, D.C., Zhang, G., Kang, L., Elser, J.J. Nutritional imbalance suppresses migratory phenotypes of the Mongolian locust (Oedaleus asiaticus). R. Soc. open sci. 2017, 4, 161039, doi:10.1098/rsos.161039. 